\title{
Restoration using Acropora cervicornis at the T/V MARGARA grounding site
}
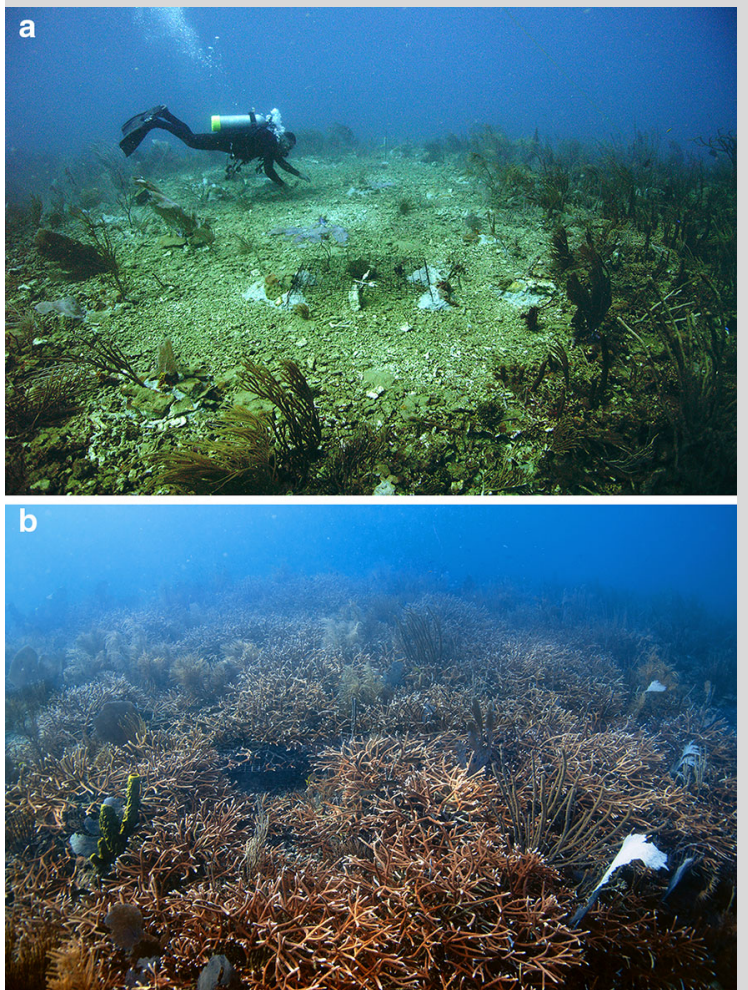

Fig. 1 Patch reef impacted by grounding in 2006 during initial restoration (a) and in January 2015 (b). Both photographs were taken from the north end of the same patch reef looking south

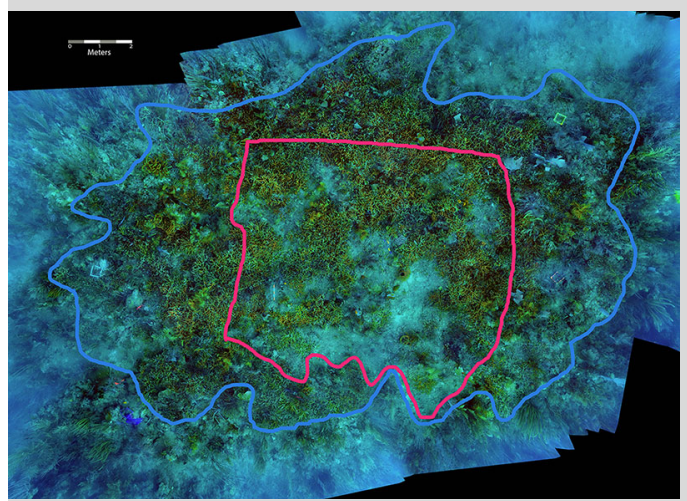

Fig. 2 Photomosaic taken in July 2014. Red polygon shows the original impact; blue polygon estimates the extent of expansion
On 27 April 2006, a 228-m oil tanker, the T/V MARGARA, grounded on coral reefs in Tallaboa, Puerto Rico, damaging approximately $7500 \mathrm{~m}^{2}$ of reef. The photographs in Fig. 1 demonstrate the success of restoration on one patch reef at the site that used a combination of reattaching loose corals, stabilizing rubble, and outplanting Acropora cervicornis from a nearby coral nursery. Restoration was performed sporadically on this reef from 2006 through 2011. Initial work from 2006 to 2008 was undertaken and funded by the responsible party. Surveys by divers during the injury assessment found no A. cervicornis on this particular patch reef prior to restoration, although it was observed in other areas of the grounding site. In 2006, 227 $(10-20 \mathrm{~cm})$ fragments of $A$. cervicornis found elsewhere in the grounding site were transferred to this patch reef and attached to wire cages and cement puddles with stakes. From 2009 through 2011, 400 (20-40 cm) colonies were outplanted from the nursery using masonry nails, cable ties, and/or epoxy. Restoration took place within the impacted section of the patch reef $\left(\sim 70 \mathrm{~m}^{2}\right)$, but A. cervicornis colonies can now be found in $\sim 180 \mathrm{~m}^{2}$ of reef (Fig. 2).

The A. cervicornis outplanted at the site have developed into a self-sustaining thicket that has been expanding via asexual reproduction and has withstood impacts from several hurricanes and swells reaching $6 \mathrm{~m}$. Other areas of the grounding site with similar characteristics in 2006 that have not yet been restored (loose rubble, unconsolidated substrate) have shown little to no recovery in the last 8 yr due to the high mortality of coral recruits in rubble fields (NOAA 2015).

Acknowledgments We would like to thank Pedro Rodriguez and Sea Ventures, Inc for providing logistical support for work at this site over the last $10 \mathrm{yr}$. We would also like to thank Art Gleason at the University of Miami for processing the photomosaic.

\section{Reference}

NOAA (2015) Final primary restoration plan and environmental assessment for the 2006 T/V MARGARA grounding. pp 59. http://www.darrp.noaa.gov/southeast/margara/ admin.html

S. P. Griffin $(\bowtie) \cdot$ M. I. Nemeth - T. D. Moore

NOAA Restoration Center, St. Petersburg, FL, USA

e-mail: sean.griffin@noaa.gov

S. P. Griffin · M. I. Nemeth

Earth Resources Technology, Inc, Laurel, MD, USA

B. Gintert

University of Miami, Coral Gables, FL, USA 